\title{
Energy/Exergy Conversion Factors of Low-Enthalpy Geothermal Heat Plants
}

Henning Francke ( $\nabla$ francke@gfz-potsdam.de)

Helmholtz-Zentrum Potsdam GFZ: Deutsches Geoforschungszentrum Potsdam

https://orcid.org/0000-0002-8086-2262

\section{Method Article}

Keywords: COP, Power-to-heat, geothermal, energy, exergy, conversion, second law efficiency, system, auxiliary energy

Posted Date: December 13th, 2021

DOI: https://doi.org/10.21203/rs.3.rs-242151/v3

License: (c) (i) This work is licensed under a Creative Commons Attribution 4.0 International License. Read Full License 


\title{
1 Energy/exergy conversion factors of low-
}

2 enthalpy geothermal heat plants

\author{
Henning Francke, GFZ German Research Centre for Geosciences \\ Keywords: Geothermal, energy, exergy, efficiency, COP, heat pump
}

\section{Abstract}

From the system perspective, a geothermal heat plant is not only a source of heat, but, in case of wells producing liquid brine (low-enthalpy), also a sink for relevant amounts of electricity, consumed mainly by the pump(s). This electricity demand is usually not given much attention, although being decisive for operation costs and offering chances for demand side management as a variable consumer. From the perspective of an integrated energy system, geothermal installations basically move energy from the electricity sector into the heat sector. So do electrical compression heat pumps, whose performance is rated by the COP, the ratio between useful heat and invested energy.

This study transfers the COP concept to geothermal sites, by defining and determining the energy conversion factor $\varepsilon$ (i.e. relative auxiliary energy or operating cost of heat provision expressed in electricity) for a selection of mostly German geothermal sites. Based on heterogenous data consisting of operational values for some sites and theoretical estimations for others, the calculated $\varepsilon$ range from 12 to 116 . In analogy, the concept is extended to the exergy conversion factor $\zeta$, which is calculated to range from 1 to 36 . A comparison with alternative heat provision technologies, such as heat pumps (COP $\leq 6)$ or simple electric heating $(\varepsilon \approx 1)$, quantifies the potential service geothermal plants can render to the grid by converting electrical energy into useful heat.

Keywords: COP, Power-to-heat, geothermal, energy, exergy, conversion, second law efficiency, system, auxiliary energy

\section{Introduction}

The integration of renewable energies into our energy system poses various challenges, among others matching the fluctuating demand and weather dependent production. Possible solutions are storage, adaptive production and curtailment, demand-side load management and energy transport over long distances. Another approach is to go beyond the electric sector and make use of other energies. Power-to- $X$ is the fashionable name for the transformation of surplus electric energy ${ }^{\mathrm{a}}$ into another energy form which can be stored better or consumed directly. Power-to-Heat is the most promising option (Drünert et al. 2019), which in its simplest form can be implemented by basically dissipating the electric energy in an electric heater. This is a very simple technology that scales well and converts nearly $100 \%$ of the input at any voltage, DC or AC, to useful heat at virtually any temperature, right where it is needed without residuals, byproducts or exhaust fumes.

The valuable electric energy can, however, be used much more efficiently for heat provision by deploying more advanced technologies, such as compression heat pumps (CHP) extracting heat from ambient or exhaust air, sewage water, soil and/or ground water using closed borehole heat exchangers or open groundwater circuits. Heat pumps are designed to provide multiples of the input power as heat output by moving heat from a low temperature heat source to a higher temperature level. Their key performance indicator is the coefficient of performance (COP), defined as heat output $\dot{Q}_{\text {out }}$ per electrical input $\dot{W}_{\text {in }}$. It is limited by the theoretical maximum, which is defined by the reversed Carnot's law:

\footnotetext{
${ }^{a}$ In Germany 20196.4 TWh (2.8\% of the electricity from renewables or $1.2 \%$ of total) were throttled(Burger 2020; Bundesnetzagentur 2020)
} 


$$
\mathrm{COP}=\frac{\dot{Q}_{\text {out }}}{\dot{W}_{\text {in }}} \leq\left(1-\frac{T_{\mathrm{c}}}{T_{\mathrm{h}}}\right)^{-1}
$$

As eq. (1) expresses, for a given heat pump technology, the COP increases with source temperature $T_{\mathrm{h}}$ and decreases with falling thermal output $\dot{Q}_{\text {out }}$. Ambient air as a heat source (ASHP) has low requirements and an unlimited heat reservoir, but also the inherent disadvantage of a low COP especially when air temperature is low and heat demand consequentially high. Eligibility for government requires COP of at least 3.1 (ASHP) and 4.3 (GSHP)(BAFA 2018), but, often installed in suboptimal conditions with excessive use of direct heating by the heating cartridge, not all ASHP can keep that promise, causing COPs to sink to 2 and below (Russ et al. 2010). Ground source heat pumps (GSHP) perform considerably better due to a more stable heat source, but require the installation of heat exchangers in the underground. However, they, too, often fail to reach their theoretical COPs in practice. One study found average values below 3.5 (Russ et al. 2010). Heat pumps for residential heating are considered to be potential actors in demand-side management (Bechtel et al. 2020).

Ground temperature and hence the realized COP generally increase with depth, but so do the technical effort and requirements. At a given depth the ground is warm enough to use the harvested heat directly without enhancing it by a heat pump. This reduces the electrical input more or less to the power consumption of circulation pumps. A closed-circuit heat exchanger although proposed on a MW scale (Winsloe et al. 2021; Toews et al. 2021) relies on heat transport by conduction (Winsloe et al. 2021) and therefore does not allow as much heat extraction as an open circuit, which exploits the convective heat transport as well. Such a closed circuit does, however, avoid the problems caused by reservoir hydraulics and precipitation of solutes from the brine.

Generally speaking, increasing the technical effort for a technology, such as increasing the depth of a geothermal well can increase the heat output, absolute and relative to the electrical input, but obviously also the financial cost (see Fig. 1).
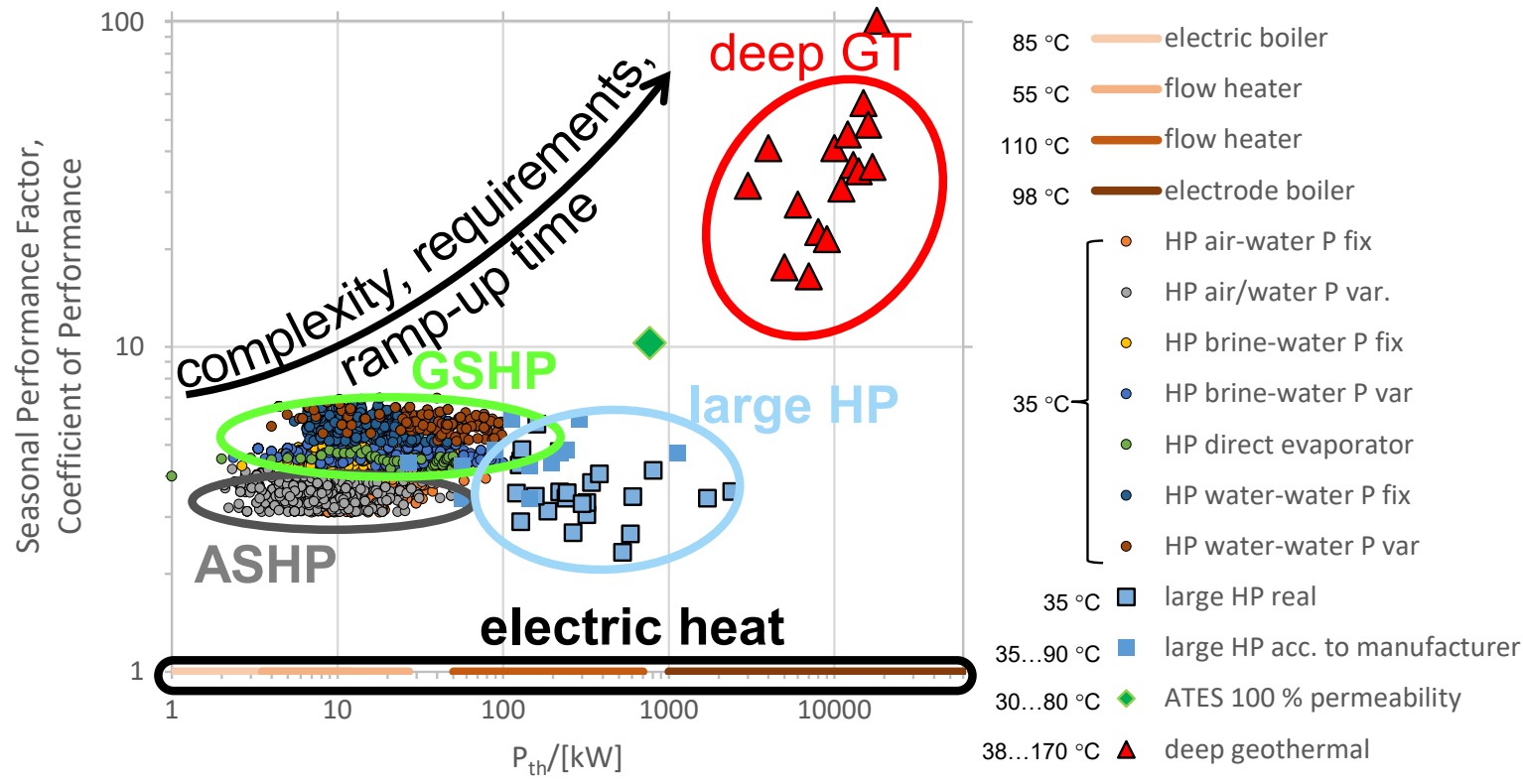

Fig. 1 Common thermal output and energetic conversion efficiencies of different heat provision technologies powered by electric energy. Values are based on test data of available devices in Germany (BAFA 2018) and installed devices in Switzerland (Hubacher et al. 2008) and on the energy conversion efficiencies of low-enthalpy geothermal plants from this publication (HP - heat pump, GHSP - ground source HP, ASHP - air source HP, GT - geothermal)

Fig. 1 also shows that while electric heaters can easily be scaled up or down without limits imposed by the working principle itself, CHPs are commonly available only up to a few dozen kW (BAFA 2018) as usually installed in single-family houses. A few large-scale heat pumps are in operation with thermal outputs up to a few MW (Hubacher et al. 2008). Beyond that range lies the domain of geothermal 
plants. Some produce from several wells at combined mass flow rates that correspond to a thermal power of hundreds of $\mathrm{MW}^{\mathrm{b}}$. They do so at a relatively smaller electrical expense, as will be shown herein.

A geothermal plant, sketched in Fig. 2 with open loop and hydrothermal reservoir, comprises one or more production wells and usually one or more injection wells. Hot (geo)fluid is produced from the underground. Unless the reservoir is hot enough to produce steam (i.e. high-enthalpy site), a production pump is required, usually a centrifugal pump installed down-hole. At the surface, heat is extracted from the geofluid, which is then reinjected via the injection well, driven by an injection pump, if required.

The recharging heat flow $\dot{Q}_{\text {in }}$ has a convective and a conductive component, which depend on reservoir hydraulics and the temperature gradient in the underground. Both are affected by well operation. $\dot{Q}_{\text {in }}$ is not necessarily in balance with the extracted heat $\dot{Q}_{\text {out }}$, i.e. the geothermal exploitation is not always sustainable in the strict sense, but rather designed for a finite duration until reservoir depletion, ideally matching the lifetime of the subsurface components. Note that $\dot{Q}_{\text {in }}$ is not considered nor mentioned further in here. It is only depicted in Fig. 2 for completeness. No equilibrium of $\dot{Q}_{\text {in }}$ and $\dot{Q}_{\text {out }}$ is assumed or required as no energy balance is formulated.

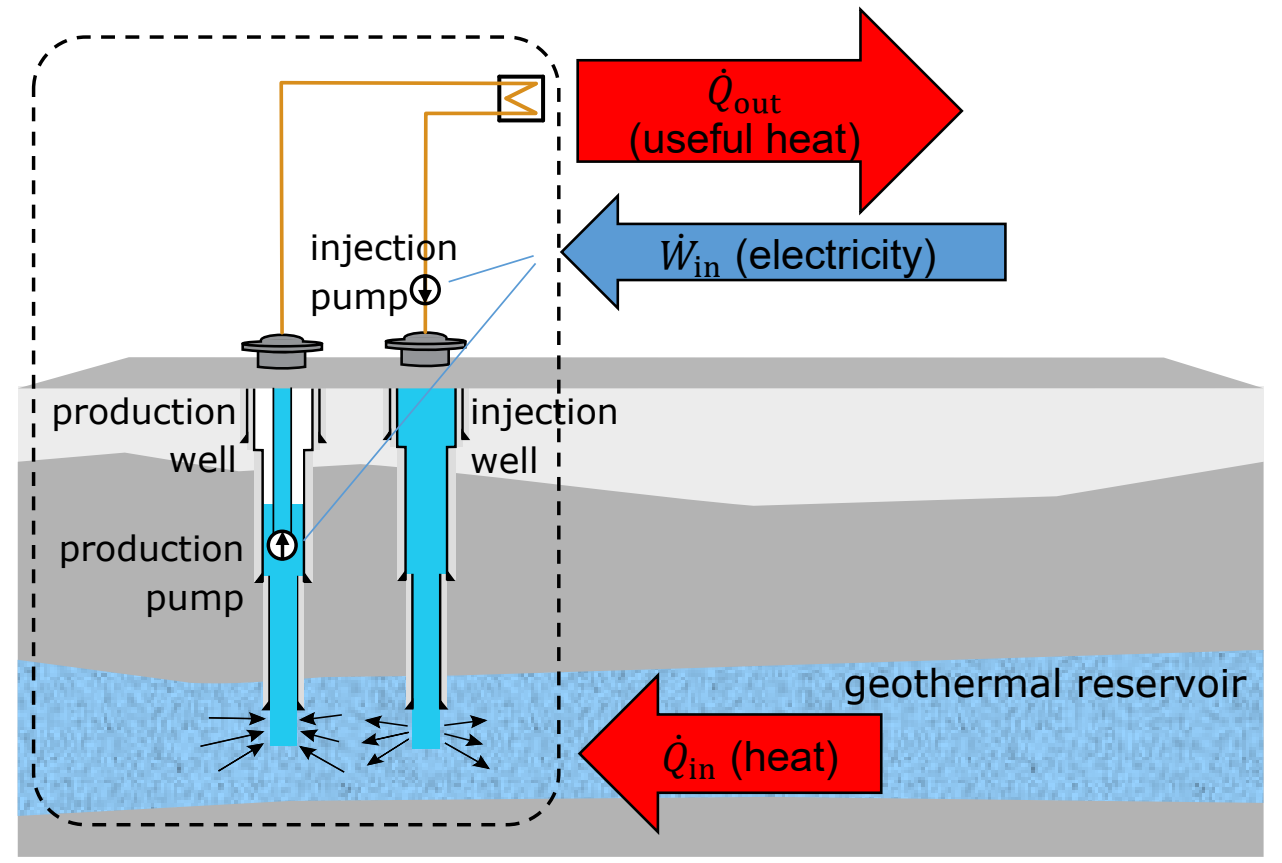

Fig. 2: Principle of a geothermal plant

Heat extraction rate obviously depends on production rate and reinjection temperature. The latter is thermodynamically limited by the temperature of the heat sink, usually being the return temperature of the secondary loop. The lower the temperature required by the heat sink, the more heat can be extracted from the geofluid. Fluid chemistry, however, adds another potential limitation. Temperature reduction may trigger precipitation, which, at the high mass flow rates realized in geothermal sites, can produce a considerable mass of solids, that at best ends up in filters and at worst clogs pipes, heat exchangers or the pores of the reservoir rock (Mouchot et al. 2018; DiPippo 2016; GTN 2010; Brehme et al. 2019).

Production rate is subject to friction, in the porous rock matrix of the reservoir as well as in the pipes of the wells and the surface installations. The complex hydraulic rock properties with respect to flow

\footnotetext{
${ }^{b}$ Several geothermal power plants at the Geysers Geothermal Field have an installed gross electrical capacity of $>100 \mathrm{MW}_{\mathrm{el}}$. This implies a thermal input of several hundreds of $\mathrm{MW}_{\mathrm{th}}$, which is produced from several wells per plant(Brophy et al. 2010).
} 
into/from a well determine the productivity/injectivity. It is quantified by the productivity/injectivity index $(\mathrm{PI} / \mathrm{II})$, defined as the ratio between flow rate and the pressure drop/increase in the well during production/injection.

The pumps have to overcome not only said friction, but also the level difference between static water table and surface plus the production well-head-pressure. Consequently, unless the production well is artesian $^{c}$ and the injection well is absorbing (creates no relevant back pressure), considerable energy is required to circulate the fluid in the geothermal circuit. This is independent of the installed pump technology, be it an ESP ${ }^{d}$, a LSP ${ }^{\mathrm{e}}$ or a piston pump.

Hence, the electrical consumption of the pumps is considerable, albeit controllable by ramping up and down the production rate and with it the heat production. Technically, this is feasible at a given maximum ramp-up speed within the boundaries of minimal partial load and maximum flow-rate. Economically it may make sense to do so given the necessary capacities in storage and/or backup heat production as well as the right economic boundary conditions which gratify operation strategies stabilizing the electric grid (Aubele et al. 2020). This upgrades geothermal heat from being a renewable energy source not causing fluctuations to one instead even compensating them, thus increasing its value as a component of an energy system. The same holds true for geothermal power plants, where the electricity production offers an additional control reserve besides their pump's consumption. Accordingly, Schlagermann predicts the shift in the operation of geothermal power plants from baseload to market oriented or even operating reserve optimized (Schlagermann 2014). Whether it is beneficial to operate an individual geothermal plant this way, is a complex question as it not only depends on the plant itself but also on the energy system characteristics. Hence, it is out of the scope of this work, but has been extensively studied by (Aubele et al. 2020).

The presented approach is applicable irrespective of useful heat application, pump technology, whether there are one or several production/injection wells, whether the reservoir is hydro/petrothermal, or whether the brine is partly/fully reinjected. The geothermal plant is simply considered as a system receiving electric energy and returning thermal energy.

This paper gives an overview about the ratio of these two quantities, i.e. the harvested heat $\dot{Q}_{\text {out }}$ relative to the auxiliary power demand $\dot{W}_{\text {in }}$ for a selection of existing geothermal sites:

$$
\varepsilon=\frac{\dot{Q}_{\text {out }}}{\dot{W}_{\text {in }}}
$$

This quantity is herein referred to as the "energy conversion factor". This $\varepsilon$ of a geothermal plant is not limited to $\varepsilon \leq 1$ by energy conservation, but rather nominally exceeds 1 . If it were below 1 , i.e. if more energy was invested than harvested, there would be no benefit over the much simpler direct transformation to heat by an electric heater having $\varepsilon=1$.

The analogy to the COP of heat pumps is obvious. Using a given amount of electrical/mechanical energy to provide a larger amount of energy as heat is the purpose of compression heat pumps (CHP). While their efficiency has the aforementioned theoretical maximum (eq. (1)), the $\varepsilon$ of a geothermal plant as defined by eq. (2) however, is not subject to this limitation derived from the fundamental laws of thermodynamics. That is due to the fact that eq. (2) is not based on a complete energy balance, as it does not consider $\dot{Q}_{\text {in }}$, but rather on the ratio output to input relevant from the energy system perspective. Hence, given an artesian or high-enthalpy steam-producing production well and an absorbing injection well, i.e. $\dot{W}_{\text {in }}=0, \varepsilon$ approaches infinity and the factor cannot be calculated.

\footnotetext{
c Flowing artesian well: the reservoir fluid pressure is high enough to make the fluid rise to the well-head, resulting in flow without pumping.

${ }^{\mathrm{d}}$ Electrical submersible pump -centrifugal pump installed together with the motor in the production well.

${ }^{e}$ Line shaft pump - centrifugal pump installed in the production well driven by a motor at the surface via a shaft.
} 
This key value $\varepsilon$ combines the thermal and the hydraulic reservoir properties, but also site-specific boundary conditions, such as pump capacity or heat exchanger performance which determine design and operating parameters, primarily reinjection temperature and production rate. In combination with a maximum thermal output $\varepsilon$ is a very simple characteristic representation of a geothermal heat plant in an energy system model. In other words, $\varepsilon$ represents the operational cost of heat provision in terms of invested electric energy, which can be converted to monetary cost or GHG emission using the specific parameters of the electricity provider. It can be used to assess the systemic potential of geothermal plants in general or to compare the energetic performance of single sites, but also, with limitations, for comparison with other heat provision technologies in a multimodal energy system.

A fair comparison of heat provision technologies, however, requires taking into account the temperature of the delivered useful heat. Heat sources with different temperature levels are not always interchangeable, because a heat source obviously needs to be warmer than the sink for the heat to flow in the right direction ( $2^{\text {nd }}$ law of thermodynamics). Hence, a warmer heat source can always replace a colder one, but not always vice versa, which makes warmer heat more valuable. This inherent "value of heat" is quantified by the exergy of the heat. ${ }^{f}$

Looking at the exergies driving and leaving the plant, the exergetic conversion factor $\zeta$ is defined in analogy to $\varepsilon$ as the ratio of thermal exergy $\dot{E}^{*}$ out output to driving electric energy $\dot{W}_{\text {in }}$, which is pure exergy. The ratio is also called "exergetic efficiency" or "second law efficiency" (Baehr \& Kabelac 2009; Backhaus \& Schlichting 1984):

$$
\zeta=\frac{\dot{E}_{\text {out }}^{*}}{\dot{W}_{\text {in }}}
$$

While the energy conversion factor $\varepsilon$ extends the concept of the COP and can be compared to it, the reference for this exergy ratio is a reversible process with $\zeta=1$, e.g. an ideal heat pump. $\zeta<1$ consequentially indicates destruction of exergy, while $\zeta>1$ marks a gain of exergy. Exergy gain is possible for the system as sketched in Fig. 2, because, again, definition eq. (3) is not based on a full exergy balance, but rather on the energy system perspective. Hence, it intentionally omits $\dot{Q}_{\text {in }}$, the inflow of exergy by heat in to the system considered here, as it is not invested in the sense that electric energy is. Furthermore, unlike a heat pump, the system considered here has no inherent exergy outflow by waste/excess heat. As for $\varepsilon$, there is no theoretical upper limit to $\zeta$.

Another obvious reference is the heat provision by an electric heater. There, the electric energy is converted completely to heat, i.e. $\dot{W}_{\text {in }}=\dot{Q}_{\text {out }}$., yet only a fraction of $\dot{Q}_{\text {out }}$ being exergy. This fraction, depends on temperature and is directly given by the Carnot factorg. If the heater were operated at a higher temperature it would destroy less exergy, but it would still be lost unless the temperature level of the final heat use also increases. The sink temperature $T_{\text {out }}$ eventually determines the system exergy loss, no matter if the loss happens by dissipation in the resistor or during transfer to the heat sink.

Even though eventually the economic profitability of a site usually is pivotal, the conversion factors give a first evaluation from the energetic/exergetic perspective how reasonable the operation of a geothermal plant can be with a systemic perspective.

\section{State of the Art}

Thoroughly characterizing geothermal sites is complex as several key parameters must be considered (DiPippo 2016), primarily the obvious parameters thermal output power and production temperature. They are determined by technical installations (well setup, pump configuration, etc.), design and operating decisions (production rate, reinjection temperature), the hydrogeological conditions (rock permeability and porosity) and, last not least, the geochemistry.

\footnotetext{
${ }^{f}$ Two heat flows $A$ and $B$ at different temperatures having equal exergy content implies that heat flow $A$ could theoretically be converted to temperature $B$ by an ideal machine, then equaling heat flow $B$.

${ }^{\mathrm{g}}$ For example, electric heating to $T_{\mathrm{out}}=100^{\circ} \mathrm{C}$ at $T_{\mathrm{amb}}=0{ }^{\circ} \mathrm{C}$, has an exergetic efficiency of 0.27 .
} 
The aquifer geometry is often simplified to a homogenous horizontal layer of rock with a given thickness. The hydraulic behavior of the aquifer (including the connection to the well) is usually linearized and described with the coefficients productivity and injectivity relating drawdown and production rate. The brine composition is thermodynamically relevant as a high salinity affects density, heat capacity and viscosity.

One way to reduce the multitude of parameters to a single value is to determine the heat generation cost in terms of money (Straubel et al. 1998; Kölbel et al. 2009; Pratiwi et al. 2018) or $\mathrm{CO}_{2}$ emissions (Pratiwi et al. 2018). This requires a usually rather extensive profitability calculation considering geological, technical and economical boundary conditions. This value can be compared against alternative heat provision technologies. Schlagermann conducted a comprehensive exergo-economic analysis for the geothermal power plant in Bruchsal, Germany, focusing on the electricity production costs (Schlagermann 2014).

While an economic calculation is certainly indispensable for the decision about the realization of a project, it is often too complex and requires too much economic input for purely energetic considerations. For this purpose, the ratio proposed here is more suitable, as it represents a relatively inexpensive and universal evaluation method with very few input parameters: Thermal output and electrical input. It is however not common to find both values. Even the reference publication for geothermal technology by (DiPippo 2016) does not give both values for any of the sites presented in detail.

While several publications investigate the energy conversion efficiency of the power cycle or the total power plant efficiencies (Moon \& Zarrouk 2015; DiPippo 2016; Eyerer et al. 2020), thereby considering the pump energy demand among others as parasitic load, only three articles are known to the author which consider it in relation to the extracted heat.

Bugai assessed a geothermal heat supply system and defined an "annual exergy efficiency factor" as the exergy of the useful heat divided by the exergy input by geothermal fluid, peak reheater and pump power supply. Yet no values are given. (Bugai 2014)

Kastner et al. took this method a step further and combined predictions of productivity and temperature to determine the energetic efficiencies (COP therein) of idealized virtual geothermal doublets in two aquifers below Berlin, Germany. They assume no heat loss in the well ( $T_{\text {prod }}=T_{\text {res }}$ ), an ideal pump, disregarding pressure loss, thermal and limitations on the consumer side. Their COP is the maximum theoretically possible energetic efficiency. It depends on both production and injection temperature ( $T_{\text {prod }}$ and $T_{\text {inj }}$ ) and on the flow rate $\dot{V}$. Kastner et al. generally assume $T_{\text {inj }}=45^{\circ} \mathrm{C}$ (based on the return temperature of a connected heating network) and determine the flow rate assuming an absorbing well without injection pump as:

$$
\dot{V}_{\text {max }}=\operatorname{II} \varrho g\left(-z_{\mathrm{wt}}\right) \text {. }
$$

This in turn requires the knowledge/assumption of the hydraulic properties of the assumed homogenous horizontal aquifer, namely the natural water table depth $z_{\mathrm{wt}}$ and the injectivity which they estimate via a porosity-permeability correlation. Kastner's approach yields rather low production rates and consequentially high conversion factors. With large uncertainties mostly due to the porosity data, they estimate the average COP, the ratio of electricity input and thermal output, to be 16.2 for the more productive one of the aquifers (Middle Buntsandstein). Their method does consider the reservoir temperature, albeit only its for the calculation of $\dot{Q}_{\text {out }}$, thus effectively equating $1 \mathrm{MW}$ at $63^{\circ} \mathrm{C}$ from the shallower aquifer with $1 \mathrm{MW}$ at $109^{\circ} \mathrm{C}$ from the deeper aquifer. (Kastner et al. 2015)

Banks et al. compiled hydraulic borehole data from a gas field. For 35 suitable wells with sufficient data and bottom hole temperatures between 65 and $152^{\circ} \mathrm{C}$ they estimated the pumping power required if a virtual power plant were to produce an arbitrarily assumed $1 \mathrm{MW}_{\mathrm{el}}$. Pump efficiency was assumed constant, conversion efficiency of the power cycle was estimated from the well temperature data using an empiric correlation. They found parasitic loads between 2 and $60 \%$. (Banks et al. 2020) 
They also list parasitic loads for a few existing plants, but not thermal power nor reinjection temperature. Vice versa, Kamila et al. list reinjection temperatures for a few other sites, but without parasitic or pump load as this would be out of scope. (Kamila et al. 2021)

\section{Method}

Most of the considered sites produce (also) electric energy. In order to include them, they are considered herein as heat plants with an attached separate power cycle (as indicated by the system boundary in Fig. 2), so that the energy conversion factor can be determined in the same way as for heat plants. The additional consumers which are part of a geothermal power plant such as cooling facility and feed pumps are not of interest here.

The energy input into a low-enthalpy geothermal heat plant is mainly consumed by the electrical consumption of the pumps $P_{\mathrm{el}}$, with the production pump usually having the biggest share.

$$
\dot{W}_{\text {in }}=P_{\mathrm{el}}^{\text {prod }}+P_{\mathrm{el}}^{\mathrm{inj}}
$$

Data of pump power consumption in geothermal sites is scarce and often considered company secret. For some sites information about net and gross electricity generation is available. The difference between the two values is a hint to the pump power consumption, but probably also includes cooling effort for the power cycle and other auxiliary consumers.

$P_{\text {el }}$ comprises the pumps' actual hydraulic work as well as mechanical and electrical losses in the pump, motor, cable and power electronics $\left(\operatorname{VSD}^{\mathrm{h}}\right)$ :

$$
P_{\mathrm{el}}=\frac{\Delta p_{\text {pump }} \cdot \dot{V}}{\eta_{\text {pump }} \eta_{\text {motor }} \eta_{\text {cable }} \eta_{\mathrm{VSD}}}
$$

If unavailable, the electrical consumption of the pumps can be estimated with eq. (6) from production rate and differential pump pressure $\Delta p_{\text {pump }}$ and assumed efficiencies.

If unknown, $\Delta p_{\text {pump }}$ can be estimated from the hydraulic work, using the productivity/injectivity index PI / II of the well, production rate $\dot{V}$, the static water table $z_{w t}<0$ and brine density $\varrho$ :

$$
\Delta p_{\text {pump }}^{\text {prod }}=\left(p_{\text {wh }}^{\text {prod }}-p_{\text {res }}\right)+\frac{\dot{V}}{\text { PI }}-\varrho \mathrm{g} z_{\text {res }}
$$

The productivity/injectivity describes the ability of a wellbore to produce/absorb fluid. It is quantified by productivity/injectivity index PI / II, defined as the ratio between flowrate per pressure drop induced by pumping at the well-bottom with respect to initial reservoir pressure $p_{\text {res }}$ :

$$
\mathrm{PI},-\mathrm{II}=\frac{\dot{V}}{p_{\text {res }}-p_{\mathrm{wb}}} .
$$

For the injection well, equation (7) is limited to $\Delta p_{\text {pump }}>0$ in order to avoid falsely calculating electricity gain in absorbing wells:

$$
\Delta p_{\text {pump }}^{\mathrm{inj}} \approx \max \left(0,\left(p_{\text {res }}-p_{\text {wh }}^{\mathrm{inj}}\right)+\frac{\dot{V}}{\mathrm{II}}+\varrho \mathrm{g} z_{\mathrm{res}}\right) .
$$

If both differential pressures $\Delta p_{\text {pump }}^{\text {prod }}$ and $\Delta p_{\text {pump }}^{\text {inj }}$ are considered in a sum and both wells are connected to the same reservoir, $p_{\text {res }}$ and $z_{\text {res }}$ cancel out leaving only the contributions by productivity/injectivity.

\footnotetext{
${ }^{\mathrm{h}}$ Variable speed drive
} 
If data about the electrical consumption of the injection pump is not available, it is assumed to be insignificant in relation to the production pump consumption. If the static water table is unknown, it is assumed to be 0 .

The harvested heat $\dot{Q}_{\text {out }}$ can be calculated as the difference of the fluid's enthalpy at both wellheads. Disregarding pressure changes, any heat losses possibly occurring in the well or between heat extraction and delivery as well as assuming one-phase flow (no gas phase), $\dot{Q}_{\text {out }}$ can be approximated by the product of production rate $\dot{m}$, a constant specific heat capacity $c_{p}$ and the temperature difference between the well heads. If the well head temperature is not available, it is assumed to equal the reservoir temperature:

$$
\dot{Q}_{\text {out }}=\dot{m}\left(h_{\text {prod }}-h_{\text {inj }}\right) \approx \dot{m} c_{p}\left(T_{\text {prod }}-T_{\text {inj }}\right) .
$$

The production rate $\dot{m}$ is assumed to equal the injection rate, i.e. there is no relevant fluid loss between production and injection, i.e. none of the produced geofluid is diverted without being reinjected and, in the case of HDR ${ }^{i}$ reservoirs, all of the produced fluid volume is injected again.

The flow rate, given as a volume flow rate $\dot{V}$, is converted to mass flow rate $\dot{m}$ with the fluid density $\varrho$ at production temperature:

$$
\dot{m}=\frac{\dot{V}}{\varrho\left(T_{\text {prod }}, X\right)} .
$$

Both $\varrho$ and $c_{p}$ of the geofluid depend on temperature and salinity $X$. In this study, their values were estimated using the brine property model BrineProp (Francke et al. 2013) considering the respective salinity $X . c_{p}$ is listed here only for reproducibility. The calculations were conducted with the specific enthalpies. Unless indicated otherwise, the mean specific heat capacity $c_{p}$ for each site was calculated from the specific enthalpies at wellhead conditions as follows:

$$
c_{p}=\frac{h\left(p_{\text {prod }}, T_{\text {prod }}, X\right)-h\left(p_{\mathrm{inj}}, T_{\mathrm{inj}}, X\right)}{T_{\mathrm{prod}}-T_{\mathrm{inj}}} .
$$

The energetic conversion factor of a geothermal plant is hence calculated by eq. (2) as

$$
\varepsilon=\frac{\dot{Q}_{\text {out }}}{\dot{W}_{\mathrm{in}}}=\frac{\dot{m}\left(h_{\text {prod }}-h_{\mathrm{inj}}\right)}{P_{\mathrm{el}}^{\text {prod }}+P_{\mathrm{el}}^{\mathrm{inj}}}=\frac{\dot{m} c_{p}\left(T_{\text {prod }}-T_{\mathrm{inj}}\right)}{P_{\mathrm{el}}^{\text {prod }}+P_{\mathrm{el}}^{\mathrm{inj}}} .
$$

In order to consider the absolute temperature or quality of the useful heat $\dot{Q}_{\text {out }}$, the exergetic conversion factor is calculated by eq. (3) as the ratio of exergy output to exergy input. The exergy $\dot{E}^{*}$ out contained in $\dot{Q}_{\text {out }}$ is calculated by applying the Carnot or quality factor ${ }^{\mathrm{j},}$ (Baehr \& Kabelac 2009). It depends on the temperature of heat provision $T_{\text {out }}$ and of the environment $T_{\mathrm{amb}}$.

$$
\zeta=\frac{\dot{E}_{\text {out }}^{*}}{\dot{W}_{\text {in }}}=\frac{\dot{Q}_{\text {out }}}{\dot{W}_{\text {in }}} \cdot\left(1-\frac{T_{\text {amb }}}{T_{\mathrm{m}}}\right) .
$$

Assuming a perfect seasonal storage, exergy depends on the minimum of the periodically varying ambient temperature (Pons 2009). The average minimum air temperature in Germany is about $-0.4^{\circ} \mathrm{C}$ (DWD 2018). This matches closely the conventional choice of $T_{\mathrm{amb}}=0{ }^{\circ} \mathrm{C}$ which is also assumed herein.

$T_{\mathrm{m}}$ is used as the upper temperature, as the brine flow is a sensible heat source. $T_{\mathrm{m}}$ is the logarithmic mean temperature of the heat transfer from the brine:

\footnotetext{
' Hot Dry Rock method, applied to petrothermal reservoirs

${ }^{\mathrm{j}}$ Here, the Carnot factor describes the amount of work achievable by a Carnot cycle operating between the brine and the ambient temperature $T_{\mathrm{amb}}$.
} 


$$
T_{\mathrm{m}}=\frac{T_{\text {inj }}-T_{\text {prod }}}{\ln \left(\frac{T_{\text {inj }}}{T_{\text {prod }}}\right)} .
$$

1 An alternative way of obtaining eq. (14) is by relating $\varepsilon$ to the COP of an ideal heat pump working 2 between $T_{\mathrm{m}}$ and $T_{\mathrm{amb}}$. This is how heat pump performance is assessed independently of temperatures, 3 albeit assuming a non-sensitive heat source ( $T_{\text {prod }}$ instead of $T_{\mathrm{m}}$ ).

$4 \quad$ The net exergy output is defined as the difference of exergy output $\dot{E}^{*}{ }_{\text {out }}$ and the electric input $\dot{W}_{\text {in }}$

\section{Sites}

Motivated by a project dealing with the German energy system, this study focuses on German deep geothermal sites and European sites with comparable low enthalpy conditions. All German sites were included where enough data could be acquired to calculate the efficiencies. All sites have in common that their wells are deeper than $1000 \mathrm{~m}$ and that they have at least one production and one injection well. The map Fig. 3 shows their locations.

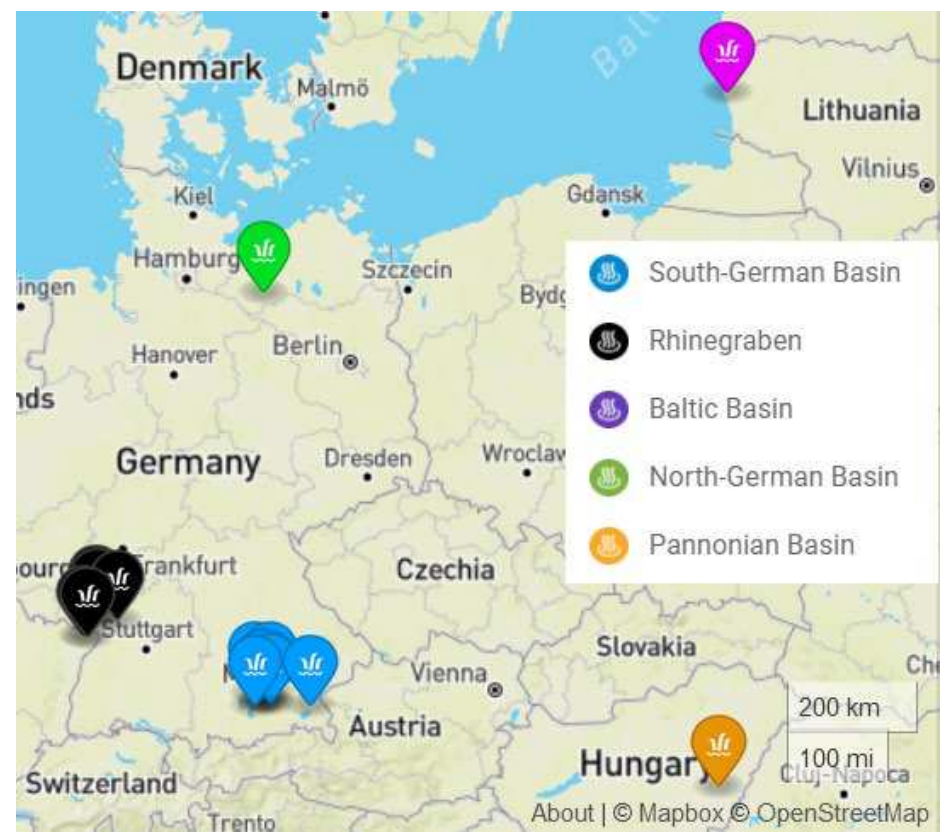

Fig. 3: Locations of the geothermal sites covered in this study (Francke n.d.)

Typical operational values were used, if available. However, the source data are very heterogeneous in quality and in what quantities were disclosed. They were acquired from publications, the GeotlS database (Agemar et al. 2014), personal communication with operators, but also from project and news websites. While values for the thermal power of geothermal sites are easily found, pump consumption data are rarely disclosed by commercial operators and if so, then often design values are given instead of actually measured ones. On the other hand, values measured as a snapshot or averaged over a limited time period, may be not representative.

As listed in Table 1 and visualized in Fig. 4 ( $\Delta T$ over $T_{\text {prod }}$ ) and Fig. $5\left(\dot{Q}_{\text {out }}\right.$ over $T_{\text {prod }}$ ), the geothermal sites considered here provide between 1 and $50 \mathrm{MW}$ of heat at production temperatures of $80 \ldots 170^{\circ} \mathrm{C}$ and reinjection temperatures of $40 \ldots 80^{\circ} \mathrm{C}$, except for the outlier Klaipeda site, which is operating at lower temperatures. 
Version: 12.12 .2021

1

- Baltic Basin • Pannonian Basin • South-German Basin • North-German Basin O Rhinegraben

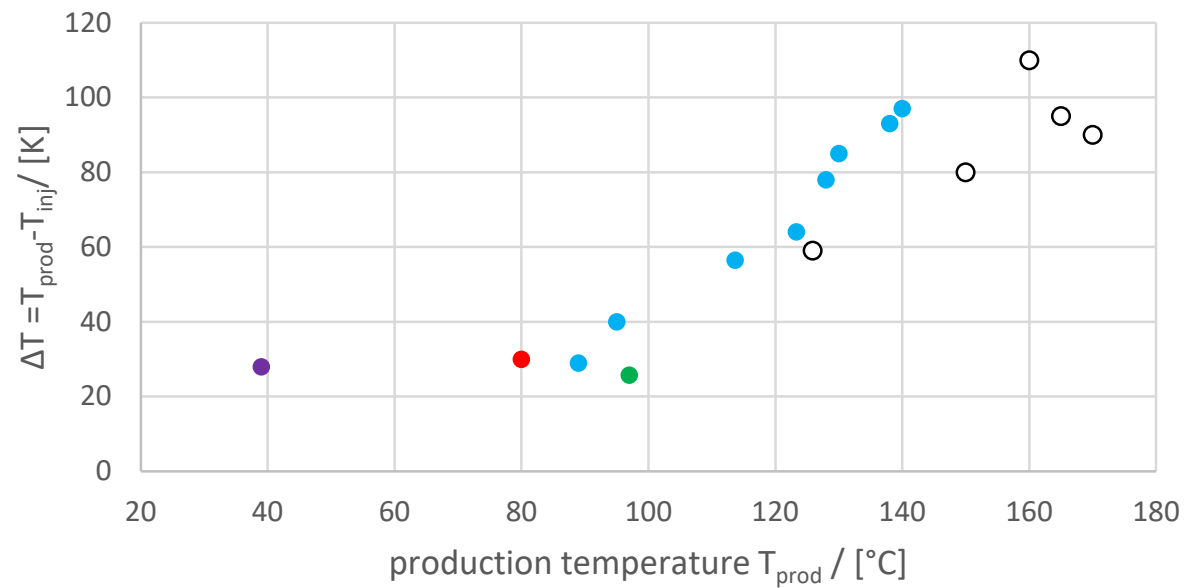

Fig. 4: Brine temperature differences between production and injection vs. production temperatures

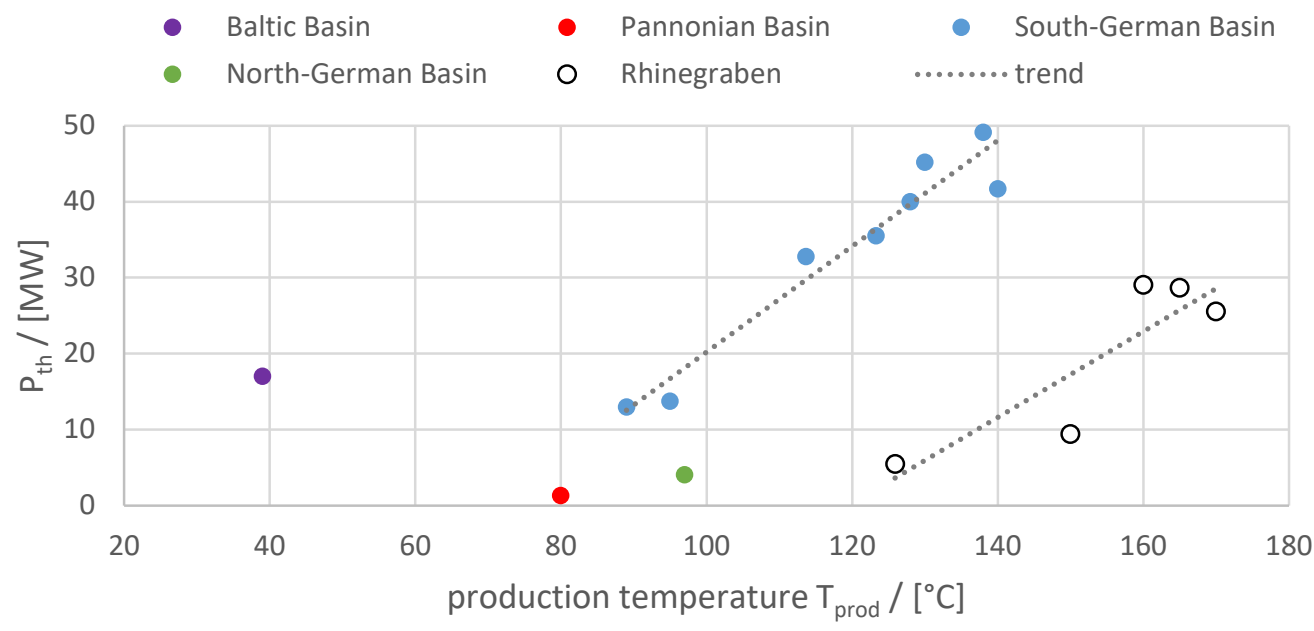

Fig. 5: Thermal output vs. production temperature. Separate linear trends plotted for sites in the SGB and NGB.

6 


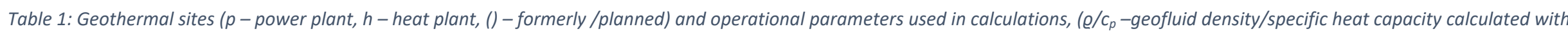
BrineProp (Francke et al. 2013), $\dot{V}$ - production rate, $P_{\text {th }}-$ thermal power extracted from the geofluid, $P_{E S P, e l}$ - electric consumption of the production pump, $P_{\text {injiel }}-$ electric consumption of the

injection pump), NGB - North-German Basin, SGB - South-German Basin, RG - Rhinegraben, BB - Baltic Basin, PB - Pannonian Basin)

\begin{tabular}{|c|c|c|c|c|c|c|c|c|c|c|c|c|c|}
\hline Site & Type & Geology & $T_{\text {prod }}$ & $T_{\text {inj }}$ & $c_{p}$ & $\varrho$ & $\dot{V}$ & $\dot{Q}_{\text {out }}$ & $P_{\mathrm{el}}^{\text {prod }}$ & $P_{\mathrm{el}}^{\mathrm{inj}}$ & $\varepsilon$ & $\zeta_{0}$ & $\zeta_{20}$ \\
\hline & & & ${ }^{\circ} \mathrm{C}$ & ${ }^{\circ} \mathrm{C}$ & $\mathrm{J} / \mathrm{kg} / \mathrm{K}$ & $\mathrm{kg} / \mathrm{m}^{3}$ & $1 / s$ & MW & MW & $\mathrm{MW}$ & & $\begin{array}{l}T_{\text {amb }} \\
=0^{\circ} \mathrm{C}\end{array}$ & $=20^{\circ} \mathrm{C}$ \\
\hline Neustadt-Glewe ${ }^{[1]}$ & $(p)+h$ & NGB & 96 & 71.3 & 3361 & 1122 & 28.8 & 2.7 & 0.16 & $?$ & 16 & 3.9 & 2.9 \\
\hline Dürrnhaar ${ }^{[2]}$ & $p+h$ & SGB & 138 & $40 \ldots 50$ & $4211 \ldots 4214$ & 928 & 135 & $46 \ldots 52$ & 1.35 & 0 & $34 \ldots 38$ & 8.7...9.2 & $6.8 \ldots 7.1$ \\
\hline Freiham $^{[2]}$ & $\mathrm{h}$ & SGB & 89 & 60 & 4190 & 966 & 110 & 12.9 & 0.73 & 0 & 18 & 3.8 & 2.7 \\
\hline Grünwald/Laufzorn & $p+(h)$ & SGB & $127^{[3]}$ & $(60)^{[4] k}$ & & & $90^{[3]}$ & $40.0^{[3]}$ & $(0.76)^{[5] !}$ & 0 & 53 & 13.3 & 10.4 \\
\hline Kirchstockach ${ }^{[2]}$ & $\mathrm{h}$ & SGB & 130 & $40 \ldots 50$ & $4205 \ldots 4209$ & 935 & 135 & $43 \ldots 48$ & 1.00 & 0 & $43 \ldots 48$ & $10.4 \ldots 11.1$ & $8.1 \ldots 8.5$ \\
\hline Riem $^{[2]}$ & $p+h$ & SGB & 95 & 55 & 4191 & 962 & 85 & 13.7 & 0.50 & 0 & 27 & 5.9 & 4.3 \\
\hline Sauerlach ${ }^{[2]}$ & $h+p$ & SGB & 140 & $38 \ldots 48$ & $4211 \ldots 4215$ & 926 & 110 & $40 \ldots 44$ & 1.20 & 0 & $33 \ldots 36$ & $8.3 \ldots 8.8$ & $6.5 \ldots 8.8$ \\
\hline Traunreut ${ }^{[6]}$ & $h+p$ & SGB & 113.7 & 57.2 & & & 146 & 34.4 & 1.31 & 0.142 & 24 & 5.3 & 4.1 \\
\hline Oberhaching ${ }^{[8]}$ & $h+(p)$ & SGB & 128 & 50 & 4209 & 935 & 140 & 43.0 & 1.30 & 0 & 33 & 8.0 & 6.2 \\
\hline Unterhaching & $p+h$ & SGB & $123.3^{[7]}$ & $59^{m}$ & 4206 & 941 & $140^{[7]}$ & $35.5^{\mathrm{n}[9]}$ & $1.65^{[9] \mathrm{o}}$ & $0^{[9]}$ & 21 & 5.3 & 4.2 \\
\hline Bruchsal ${ }^{[10]}$ & $p+h$ & RG & 126 & 66.8 & & & 24 & 5.4 & 0.13 & 0 & 41 & 10.6 & 8.4 \\
\hline Insheim ${ }^{[8]}$ & $p+h$ & RG & 165 & 70 & 3837 & 982 & 80 & 28.6 & $(0.80)^{\mathrm{p}}$ & 0 & 36 & 10.6 & 8.8 \\
\hline Landau $^{[8]}$ & $\mathrm{h}$ & RG & 160 & 50 & 3837 & 982 & 70 & 29.0 & $(0.60)^{p}$ & 0 & 48 & 13.2 & 10.6 \\
\hline Rittershoffen ${ }^{[11]}$ & $p$ & RG & 170 & 80 & 3915 & 968 & $72 \ldots 77$ & $25 \ldots 26$ & $(0.21 \ldots 0.31)^{q}$ & 0 & $86 \ldots 116$ & $26.8 \ldots 36.0$ & $22.5 \ldots 30.1$ \\
\hline Soultz-sous-Forêts ${ }^{[11]}$ & $\mathrm{h}$ & RG & 150 & 70 & 3907 & 983 & 31 & 9.4 & $(0.17)^{[13] q}$ & 0 & 56 & 16.0 & 13.1 \\
\hline Klaipeda $^{[14]}$ & $\mathrm{h}$ & BB & 36 & 11 & $3844^{[15]}$ & $1054^{[15]}$ & 168 & 17 & $0.055^{r}$ & 0.55 & 28 & 2.2 & 0.31 \\
\hline Mezőberény ${ }^{[16]}$ & $(p)+h$ & PB & 80 & 50 & 4177 & 975 & $8.3 \ldots 12.8^{s}$ & $1.0 \ldots 1.6^{t}$ & $0.013 \ldots 0.03$ & $0.005 \ldots 0.012^{u}$ & $36 \ldots 48$ & $6.9 \ldots 9.2$ & $4.8 \ldots 6.4$ \\
\hline
\end{tabular}

${ }^{k}$ Assumption based on heating network return temperature of $55^{\circ} \mathrm{C}$

'Linear interpolation for indicated flow rate from nominal values $1.350 \mathrm{MW}$ at

$160 \mathrm{l} / \mathrm{s}^{6}$

${ }^{m}$ Calculated with eq. (10)

${ }^{\mathrm{n}} 38 \mathrm{MW}$ is valid at $150 \mathrm{l} / \mathrm{s}$, here scaled to actual production rate

- Including losses in motor, cable and variable-frequency drive

${ }^{\mathrm{p}}$ Assumption made in the data source

${ }^{\mathrm{q}}$ Calculated as $P_{\mathrm{el}}^{\text {prod }}=\dot{V}^{2} / P I / \eta$, where $\eta_{\text {prod }}=0.7$ and $\mathrm{PI}=0.8 \mathrm{l} / \mathrm{s}$ (Soultz) or $2.8 \ldots 3.5 \mathrm{l} / \mathrm{s}^{23}$ (Rittershofen)
${ }^{r} \mathrm{PI}=\| 1 \cdot 10=73$ according to (Eyerer et al. 2020), natural water level = sea level, surface at $9 \mathrm{~m}$

s Nominal volume flow rate of the two main circulation pumps vs. design flow rate of the plant.

${ }^{t}$ Nominal power of main heat exchanger is given as $533 \mathrm{~kW}$, while thermal power calculated from temperature difference and flow rate amounts to $1018 \mathrm{~kW}$

"No injection pump, includes compressor, pressure boosting pump block and heat exchanger circulation pump 


\section{List of references in Table 1:}

[1] (Schallenberg et al. 1999)

[2] (Pietl, (Stadtwerke München) 2018)

[3] (Agemar 2014a)

[4] (Bauer et al. 2014)

[5] (\{Erdwärme Grünwald GmbH $\}$ 2013)

[6] (Giese, (Grünwald Equity) 2018)

[7] (Agemar 2014b)

[8] (Eyerer et al. 2020)

[9] (Geisinger, (Geothermie Unterhaching) 2018)

[10](Schlagermann 2014)

[11](Mouchot et al. 2018)

[12](Baujard et al. 2017)

[13](BINE Informationsdienst 2009)

[14] (Brehme et al. 2019)

[15] (GTN 2010)

[16](TRIO-CORD KFT. 2012)

Table 1 lists the key parameters of the included geothermal sites as well as the calculated energy and exergy conversion factors. Where the in put parameters were available as ranges or in several variants, they are listed as a value range of the resulting conversion factors.

Fig. 6 plots the energy conversion factors $\varepsilon$, whereas Fig. 7 plots the exergy conversion factors $\zeta$ for all included sites. The value range is indicated by the respective mean value with error bars. Fig. 8 shows the conversion factors plotted against the production temperature as well the Carnot factor as a reference representing the exergetic efficiency of electric heating working at the given temperature.

$\square$ Baltic Basin Pannonian Bsn. $\square$ Sth.German Bsn. Nth.German Bsn. $\square$ Rhinegraben

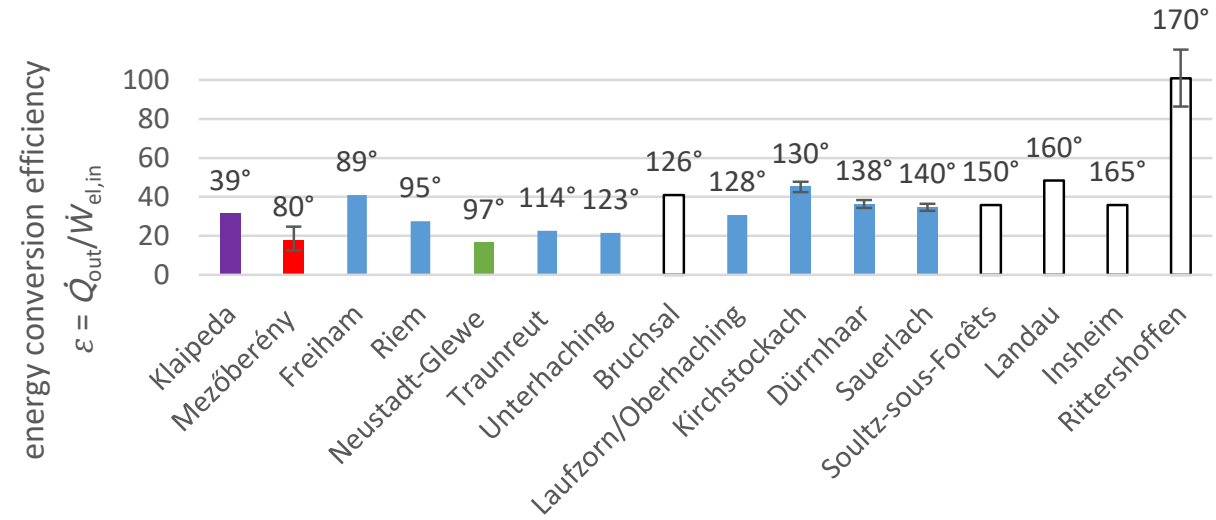

Fig. 6: Energy conversion factors (mean values with error bars indicating the value range) for selected geothermal sites, sorted and annotated by production temperature 
Baltic Basin $\square$ Pannonian Bsn. - Sth.German Bsn. $\square$ Nth.German Bsn. $\square$ Rhinegraben

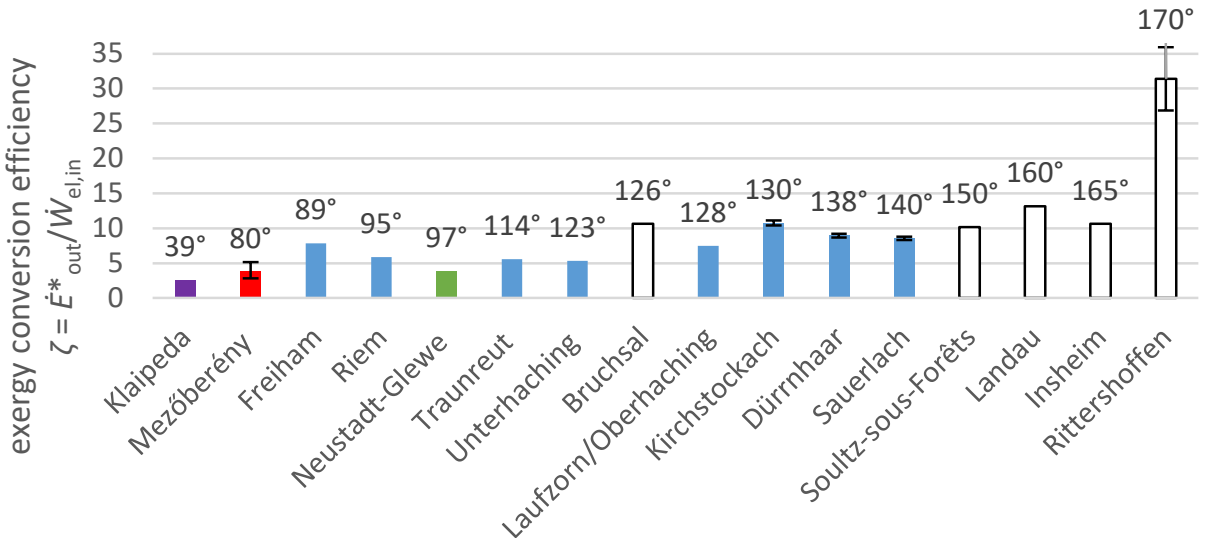

Fig. 7: Exergy conversion factors (mean values with error bars indicating the value range) for selected geothermal sites at an ambient temperature of $0^{\circ} \mathrm{C}$., sorted by and annotated with production temperature.

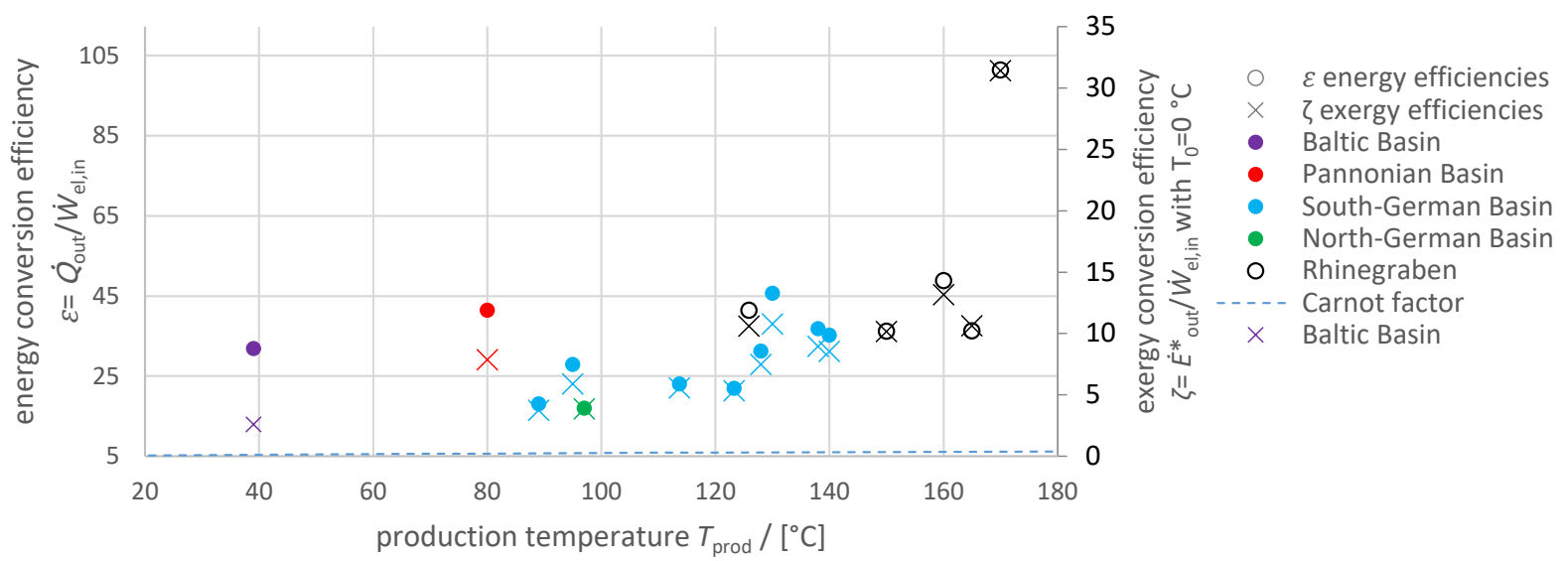

Fig. 8: GT plants: conversion factors vs. production temperature (exergy reference temperature $T_{0}=0^{\circ} \mathrm{C}$, axis scaled to make $\varepsilon$ plot match $\zeta$ plot for sites with $\mathrm{min} /$ max efficiencies), Carnot factor representing the exergetic efficiency of electric heating.

Eqs. (5)-(15) describe a simple analytic model of a GT plant which can be used to explain the nonlinear influence of the production rate on the conversion factors and thus put the real-world values presented later into context. Applying this simple model to a range of production rates with a given set of parameters produces the data plotted in . 


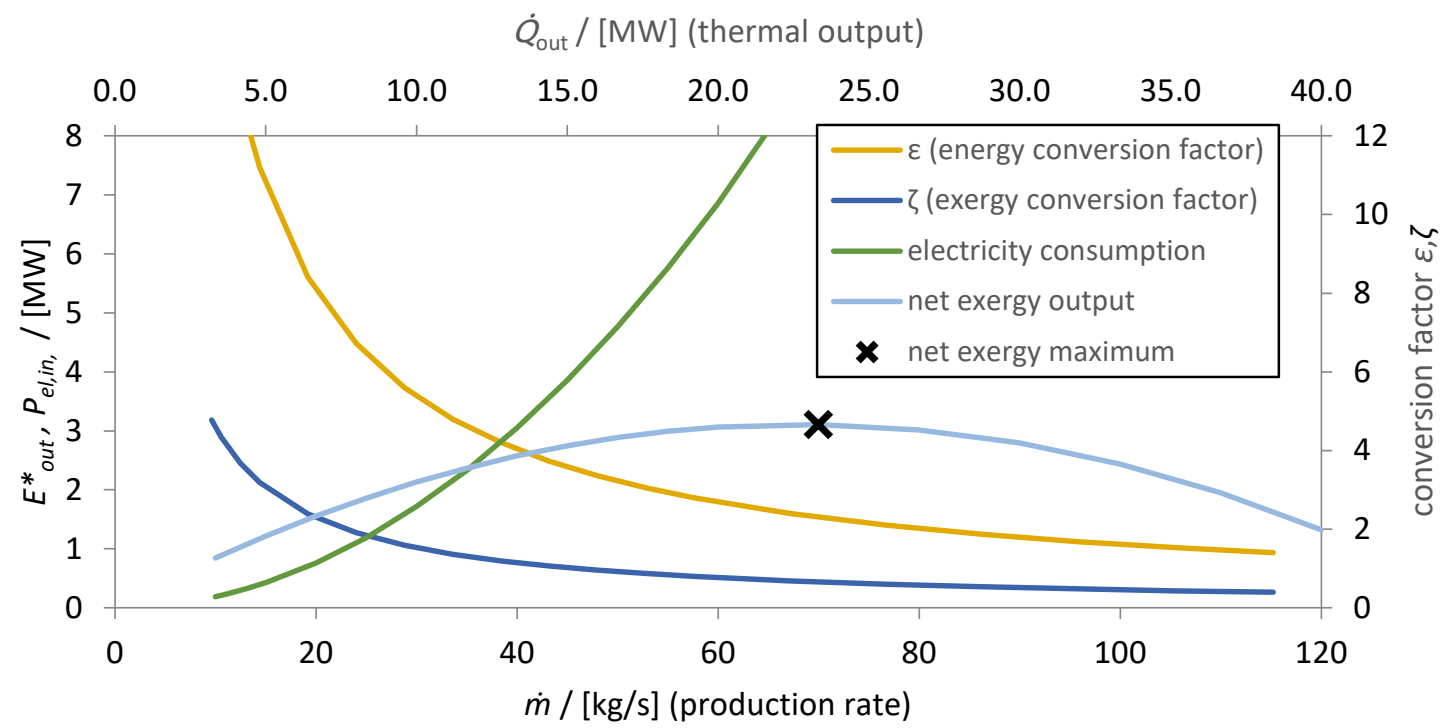

Fig. 9: Conversion factors as a function of production rate for a fictional site $\left(W H T=150^{\circ} \mathrm{C}, \Delta T=80^{\circ} \mathrm{C}, \mathrm{PI}=5.4 \mathrm{~m}^{3} / \mathrm{h} / \mathrm{MPa}\right.$, $\left.c_{p}=4 \mathrm{~kJ} / \mathrm{kg} / \mathrm{K}, \varrho=1000 \mathrm{~kg} / \mathrm{m}^{3}\right)$

\section{Discussion}

According to the model equations visualized in Fig. 1Fig. 9, production rate grows proportionally with thermal output (indicated by the second abscissa), while pump effort increases quadratically, thus reducing the resulting conversion factors. Hence, the operating point yielding the highest net exergy output will be a tradeoff between thermal output and the energetic/exergetic conversion factor. As visualized by its broad maximum, there may be a point within the feasible operation range beyond which a further increase of production will cost more exergy in the form of electricity than is gained from additional provided heat. The flat curve, however, indicates a low sensitivity to a change of production rate around the maximum, which makes the choice less critical.

Before elaborating on the calculated conversion factors, note that this study aims at giving a first overview of the conversion factors realized in actually operating geothermal plants. The heterogeneity of the source data should be kept in mind when comparing the sites, especially when the sources are polished websites or optimistic press releases. Furthermore, a single datapoint per site can only be a snapshot or an average of variable quantities. On the other hand, off-design operation can decrease the conversion factor, as pump efficiency will be reduced outside of their design operation range or fluid friction in the well becomes relevant if the diameter is small. Finally, the calculated conversion factors are not meant as a rating of the plant design and construction as they are also a consequence of boundary conditions given by thermo-hydraulic aquifer properties as well as limitations imposed by the fluid chemistry.

The geothermal sites considered here show a wide range of energy conversion factors $\varepsilon$ between 12 and 112 (Fig. 6). This matches roughly the theoretical values determined by Kastner et al.: between 6 and 21 for the Middle Buntsandstein and between 43 and 74 for the Rotliegend (Kastner et al. 2015) formation.

Similarly, in Fig. 7 the exergy conversion factors $\zeta^{0^{\circ} \mathrm{C}}$ show a broad distribution with values ranging from 1 to 36. Fig. 6 and Fig. 7 look quite alike except for the Klaipeda, where the low production temperature takes its toll on the exergy placing it lowest.

Before looking closer at single sites, comparing these ranges to the COPs and $\zeta$ of compression heat pumps (CHP) with air/ground as low-temperature heat source yields a clear result: The energy conversion factors $\varepsilon$ of GT plants are roughly one order of magnitude above COPs of common CHPs 
(COP $\approx 2 \ldots 6$ when providing heat at $35^{\circ} \mathrm{C}$ ) (BAFA 2018),, , while delivering heat at usually higher temperatures. The $\zeta$ of an ideal heat pump is by definition 1 , which is $1 . .2$ orders below the $\zeta$ of the GT plants considered here. Let alone electrical heating with a $\zeta<1$, given by the Carnot factor, which is plotted in Fig. 8 clearly below even the lowest plant $\zeta$. This suggests that deep geothermal heat exploitation offers a highly efficient way of using electricity to provide heat.

Before comparing the site performances, the thermal boundary conditions are worth a second look. Plotting the brine temperature differences between production and injection $\Delta T$ against $T_{\text {prod }}$ in Fig. 5 clearly shows a positive trend. So does plotting $\dot{Q}_{\text {out }}$ against $T_{\text {prod }}$ in Fig. 5 , yet not over all sites, but within the two distinct regions that contain several sites. The sites in South-German Basin produce more heat than the ones in the Rhinegraben due to higher $\dot{V}$ in spite of lower $T_{\text {prod. }}$. The small sample numbers do not allow conclusions for the other regions or with respect to different regions. Given the linear relation between $\dot{Q}_{\text {out }}$ and $\Delta T$ in eq. (10), the observed positive trend is expected (unless countered by a decrease of $\dot{V}$, which is not the case here).

Fig. 8 also shows a general positive trend w.r.t. $T_{\text {prod }}$ of both $\varepsilon$ and $\zeta$. Different from Fig. 5 however, the trend within the Rhinegraben region, is not clear. Again, a positive trend can be expected given the positive contribution from $\dot{Q}_{\text {out }}$, and, in the case of $\zeta$, from the Carnot factor. Exceptions from the positive trend are caused by either a high $T_{\mathrm{inj}}$, high electrical consumption due to a low productivity/injectivity or bad performance for other reasons. The offsets between the mid-range $\varepsilon$ and $\zeta$ are caused by the non-linear temperature dependence of the Carnot factor in eq. (14) and the logarithmic mean in eq. (15).

The $\zeta$ listed and plotted above have been determined for the common yet arbitrarily chosen reference temperature $T_{\mathrm{amb}}=0{ }^{\circ} \mathrm{C}$. Having the lowest production temperature, Klaipeda's $\zeta$ is most sensitive to a change of $T_{\mathrm{amb}}$ of all sites. Recalculating Klaipeda's $\zeta$ with the reference $T_{\mathrm{amb}}=20^{\circ} \mathrm{C}$ lowers it to 0.31 , while all other sites remain well beyond $\zeta=1$ with values ranging from 2.7 to 30 . $\zeta=0.3$ is in the lower range of what current CHPs achieve, as the exergetic efficiencies derived from a comprehensive list of CHP of different technologies available on the German market (BAFA 2018) show $\zeta$ between 0.33 and 0.64 for $T_{\mathrm{amb}}=0{ }^{\circ} \mathrm{C}$ or $2{ }^{\circ} \mathrm{C}$. Other sources give values between 0.28 and 0.5 (Russ et al. 2010). This assessment shows that the operation of the Klaipeda site would be exergetically reasonable if it were operating with the listed parameters. However, it is not, due to declining productivity caused by precipitation in spite of counter-measures, which is why the plant operation indefinitely ceased operation in March 2017 (Šliaupa et al. n.d.; Brehme et al. 2019).

The remarkably high conversion factors of the Rittershoffen site can be explained with high production temperature and low pumping demand to begin with, but possibly also with the fact that it is based on estimation rather than on operational measurements. Pump power for both this site and the one in Soultz have been estimated only from the well productivity, thus neglecting additional work caused by the static water table level, high well head pressure and friction within the brine circuit. Hence, the real conversion factors can be expected to be lower. Vice versa, the low factors of Klaipeda, Neustadt-Glewe and Freiham are a consequence of low production temperature and relatively high electricity consumption by the pumps. A detailed analysis of the individual reasons is out of the scope of this work

Applying the same method to the partly theoretical data compiled by (Banks et al. 2020) results in an even wider range of $\varepsilon=3 \ldots 207(\bar{\varepsilon}=33)$, which corresponds to $\zeta^{0^{\circ} \mathrm{C}}=0.6 \ldots 50\left(\bar{\zeta}^{\circ{ }^{\circ} \mathrm{C}}=7.8\right)$. The high values result from very productive, nearly artesian wells in the gas field. For a real power plant, they would probably be operated at a higher production rate, thus yielding more output at lower conversion rates. Vice versa, the five wells with the lowest conversion rates would not be operated as assumed, because their pump power exceeds the produced electricity, as their temperatures are below $80^{\circ} \mathrm{C}$.

\footnotetext{
${ }^{v}$ Note that, by definition, the heat pump COP does not include the auxiliary electric energy for heat provision, e.g. for circulating the fluid through the heat collector. Similarly, the conversion factors $\varepsilon$ and $\zeta$, due to limited data availability, in most cases also only consider the main consumers of auxiliary electric energy, namely the pumps for production and reinjection.
} 
Heat provision could still make sense energetically, even from the "worst" two wells at a supposedly suboptimal production rate, as, with an $\varepsilon=\{3.1,4.1\}$ they are en par with common CHPs.

\section{Conclusion}

Geothermal heat is available independently of weather conditions. It may be considered as free of charge, but its exploitation certainly requires investment, not only of money, but also of energy. From the system perspective, geothermal plants are commonly only considered as heat sources. However, they require pumps to produce and/or reinject the geofluid, unless they operate under special circumstances (i.e. high-enthalpy steam producing reservoir and reinjection of condensed liquid or artesian production well and no reinjection). These pumps consume considerable amounts of valuable electricity, with their nominal powers often amounting to several hundreds of $\mathrm{kW}$. Without formulating a complete energy balance, this study relates this electricity input to the thermal output in terms of energy and exergy based on the gathered production data of a selection of geothermal sites. The differing temperatures of the delivered heat are considered by calculating the respective exergy contents. The conversion factors calculated here show that extracting heat from the underground is a very efficient use of electricity, even though this ratio output/input varies by one order of magnitude among the sites considered in this study. Far more heat and exergy is provided than invested as electrical input, which, from the system perspective, makes GT plants basically very effective Power-to-Heat converters and as such, valuable links coupling the sectors of electricity and heat.

Hence, given the appropriate part-load capability and flexible heat demand and/or heat storage capacity, GT plants could serve as flexible electrical load that could be activated or shed depending on the availability of cheap surplus electricity.

The purpose of the definition of the conversion factors is to describe the efficiency of the system at a specific moment in time rather than over its lifetime. Such a lifetime assessment would require other much more extended investigations which would not significantly change the conclusions of this paper. Nevertheless, this may be a future topic for fine tuning the view on the efficiency of geothermal plant operation.

The exergetic conversion factor used in here can be helpful as a key parameter to characterize geothermal plants in strongly simplified energy system models. This allows a comparison to other methods of electrically powered heat provision such as electric heating or CHPs. For this and other purposes it would be beneficial to include the pump power consumption to overview tables and databases (DiPippo 2016; Agemar et al. 2014; Anon n.d.), which usually lack it ${ }^{\mathrm{w}}$, compiling only other key figures such as thermal/electric power, production rate and temperature.

However, similar to the efficiency of a geothermal power cycle, the conversion factors are not the quantities to be maximized by varying mass flows, as this would lead to small thermal output. More reasonable is maximizing the net exergy output. Its maximum may help to identify the "sweet spot" with respect the production rate independent from economic parameters.

\section{Outlook}

Including more sites in this assessment would potentially allow to draw further conclusions, e.g. by correlating the conversion factors to plant design or operational parameters or clustering them by geologic setting.

Considering geothermal plants as sinks for surplus electricity raises the question of their part load performance and their part load ability, i.e. how far and how quickly can their output be reduced or increased. This should be quantified and be used as additional key parameters to describe geothermal plants from the perspective of the energy system.

\footnotetext{
w The OpenEl online database(Anon n.d.) has a field for „parasitic load“, but no data
} 
The assessment method presented here could be extended from existing geothermal plants to existing boreholes or even to unexploited geothermal reservoirs, founding on existing data of geothermal potential (Wolfgramm et al. 2009). Following (Kastner et al. 2015), the energetic/exergetic conversion factor could be calculated based on the well productivity/injectivity, the water table and the reservoir temperature. Discarding the limitation in eq. (9), eq. (13) would then be adapted as follows:

$$
\varepsilon=\frac{\varrho c_{p}\left(T_{\text {prod }}-T_{\text {inj }}\right)}{\left(\mathrm{PI}^{-1}+\mathrm{II}^{-1}\right) \dot{V}} .
$$

As described in the "state of the art", this approach would yield rather high efficiencies at a small production rate (its maximum without an injection pump.) Another choice for the mass flow could be on the other end of the range: The maximum production rate limited by the maximum drawdown with the lowest possible production pump installation depth, which is reservoir depth. Besides the presence of an injection pump, that implies a dynamic water table lowered to the minimum height above the pump, which is the required net pump suction head $\mathrm{NPSH}_{\mathrm{R}}$ :

$$
\dot{V}_{\text {max }}=\operatorname{PI} \varrho g\left(z_{\mathrm{wt}}-z_{\text {res }}-\mathrm{NPSH}_{\mathrm{R}}\right)
$$

Consequentially, this approach would return rather high flowrates, low efficiencies, and, assuming PI = II, cancel the productivity from the equation only leaving the depths and the temperatures.

The practical optimum for production rate is somewhere between these two values, determined by a variety of boundary conditions, e.g. geologically motivated pressure limits, demand side requirements, financial deliberation or optimal net power output (Frick et al. 2010). With this information being unknown for non-existent plants, an educated guess for the design operating point could be made using the net exergy maximum as discussed before. The same may apply for an economic optimum as both electricity demand and heat production can be converted into cost and revenue. This economic optimum may, however, be offset w.r.t the net exergy output maximum, as it depends on the monetary parameters.

The presented conversion efficiencies can be calculated for any electrically driven heat provision technology, including geothermal sites operated as thermal storages (ATES, BTES, MTES ${ }^{x}$. Like the storage efficiency, the conversion factor could serve as key figure to assess different storage technologies or to compare storage to other heat/cold provision technologies. Eq. (13) should then be changed to include the energy invested for storing the heat/cold.

\begin{tabular}{|c|c|c|}
\hline COP & 1 & Coefficient of Performance \\
\hline$c_{p}$ & $\mathrm{~J} /(\mathrm{kg} \cdot \mathrm{K})$ & specific heat capacity \\
\hline$\dot{E}_{\text {out }}^{*}$ & $\mathrm{~W}$ & exergy output \\
\hline g & $\mathrm{N} / \mathrm{kg}$ & gravitational acceleration \\
\hline$h_{\text {prod }}, h_{\text {inj }}$ & $\mathrm{J} / \mathrm{kg}$ & specific enthalpy at production, injection well-head \\
\hline II & l/s/MPa & Injectivity index \\
\hline$\dot{m}$ & $\mathrm{~kg} / \mathrm{s}$ & mass flow rate \\
\hline$\Delta p_{\text {pump }}$ & $\mathrm{Pa}$ & differential pump pressure \\
\hline$p_{\mathrm{amb}}$ & $\mathrm{Pa}$ & ambient pressure (= 1 bar) \\
\hline$P_{\mathrm{el}}$ & W & electrical power consumption \\
\hline PI & l/s/MPa & productivity index \\
\hline
\end{tabular}

\section{Nomenclature}

\footnotetext{
${ }^{x}$ Aquifer/Borehole/Mine Thermal Energy Storage
} 


$\begin{array}{rlll}1 & p_{\text {wh }}^{\text {prod }}, p_{\text {wh }}^{\text {inj }} & \text { Pa } & \text { well-head pressure } \\ 2 & T_{\text {prod }}, T_{\text {inj }} & \mathrm{K} & \text { well-head temperature production, injection } \\ 3 & T_{\text {amb }} & \mathrm{K} & \text { ambient temperature } \\ 4 & T_{\mathrm{m}} & \mathrm{K} & \text { mean temperature of heat transfer } \\ 5 & T_{\text {out }} & \mathrm{K} & \text { temperature of heat output } \\ 6 & \dot{W}_{\text {in }} & \mathrm{W} & \text { input power to the brine circuit } \\ 7 & \dot{Q}_{\text {out }} & \mathrm{W} & \text { thermal power extracted from the brine circuit } \\ 8 & \dot{V} & \mathrm{~m}^{3} / s & \text { Flowrate, production rate } \\ 9 & X & \mathrm{~kg} / \mathrm{kg} & \text { brine salinity } \\ 10 & Z_{w t} & \mathrm{~m} & \text { natural water table / hydraulic head } \\ 11 & \varepsilon & 1 & \text { energetic conversion factor } \\ 12 & \zeta & 1 & \text { exergetic conversion factor } \\ 13 & \eta & 1 & \text { energetic efficiency } \\ 14 & \varrho & \mathrm{kg} / \mathrm{m}^{3} & \text { fluid density }\end{array}$

\section{Declarations}

\section{Availability of data and material}

The collected data is provided as supplementary spreadsheet files

The author is employed by an institution conducting research in and advocating geothermal energy.

\section{Funding}

This work was funded by the Initiative and Networking Fund of the Helmholtz Association in the future topic "Energy Systems Integration" under grant number ZT-0002.

\section{Authors' contributions}

24 Not applicable.

\section{Acknowledgements}

The author is grateful to the plant operators that provided helpful information.

\section{References}

\{Erdwärme Grünwald GmbH\}. 2013. Die neue EWG-Tiefenpumpe geht in Betrieb. www.erdwaermegruenwald.de/Startseite/Informationen-Medien/Informationen/News-Archiv/E1120.htm [Accessed March 2, 2018].

Agemar T (LIAG). 2014a. GeotlS - Geothermal Installation Grünwald (Laufzorn). 
Aubele K, Baumann T, Dawo F et al. 2020. Flexibilitätsoptionen der Strom-und Wärmeerzeugung mit Geothermie in einem von volatilem Stromangebot bestimmten Energiesystem Abschlussbericht, Umweltbundesamt. $385 \mathrm{p}$.

Backhaus U \& Schlichting HJ. 1984. Der exergetische Wirkungsgrad. In: Der Physikunterricht 18/3. p. 58-61.

Baehr HD \& Kabelac S. 2009. 3 Der 2. Hauptsatz der Thermodynamik. In: Thermodynamik. Berlin: Springer Berlin Heidelberg.

BAFA. 2018. Erneuerbare Energien - Wärmepumpen mit Prüfnachweis, Bundesamt für Wirtschaft und Ausfuhrkontrolle. p.

Banks J, Rabbani A, Nadkarni K et al. 2020. Estimating parasitic loads related to brine production from a hot sedimentary aquifer geothermal project: A case study from the Clarke Lake gas field, British Columbia. Renew Energy, 153:539-552. doi:10.1016/j.renene.2020.02.043.

Bauer M, Freeden W, Jacobi H et al. 2014. Handbuch Tiefe Geothermie, Berlin / Heidelberg: Springer Spektrum. 854 p.

Baujard C, Genter A, Dalmais E et al. 2017. Hydrothermal characterization of wells GRT-1 and GRT-2 in Rittershoffen, France: Implications on the understanding of natural flow systems in the rhine graben. Geothermics, 65:255-268. doi:10.1016/j.geothermics.2016.11.001.

Bechtel S, Scholzen F, Rafii-Tabrizi S et al. 2020. Demand-Side-Management Potentials for Heat Pumps in Residential Buildings. In: Proceedings of Building Simulation 2019: 16th Conference of IBPSA. IBPSA, p. 19341940.

BINE Informationsdienst. 2009. Geothermal electricity generation in Soultz-sous-Forêts, Karlsruhe/Bonn. 1-4 p.

Brehme M, Nowak K, Banks D et al. 2019. A Review of the Hydrochemistry of a Deep Sedimentary Aquifer and its Consequences for Geothermal Operation: Klaipeda, Lithuania. Geofluids. doi:10.1155/2019/4363592.

Brophy P, Lippmann M, Dobson PF et al. 2010. The Geysers Geothermal Field Update 1990/2010, Berkeley, CA (United States). p.

Bugai V. 2014. Exergy and Economic Analysis of Effectiveness of Geothermal Heat Supply Systems. In: ThirtyNinth Workshop on Geothermal Reservoir Engineering. Stanford University, p. 1-4.

Bundesnetzagentur. 2020. Quartalsbericht Netz- und Systemsicherheit - Gesamtes Jahr 2019, Bonn. p.

Burger B. 2020. Öffentliche Nettostromerzeugung in Deutschland 2019: Mehr erneuerbare als fossile Energieerzeugung, Freiburg. 4 p.

DiPippo R. 2016. Geothermal Power Generation: Developments and Innovation 3rd ed., Elsevier Ltd. 1-822 p.

Drünert S, Neuling U, Timmerberg S et al. 2019. Power-to-X (PtX) aus „Überschussstrom“ in Deutschland Ökonomische Analyse. Zeitschrift für Energiewirtschaft, 43:173-191. doi:10.1007/s12398-019-00256-7.

DWD. 2018. Deutscher Klimaatlas. www.dwd.de/DE/klimaumwelt/klimaatlas/klimaatlas_node.html [Accessed July 10, 2018].

Eyerer S, Schifflechner C, Hofbauer S et al. 2020. Combined heat and power from hydrothermal geothermal resources in Germany: An assessment of the potential. Renew Sustain Energy Rev, 120:109661. doi:10.1016/j.rser.2019.109661.

Francke H. Map of geothermal sites covered in this study. http://geojson.io/\#id=gist:Heineken/b9531cf5f2a6e4cfe7789ea3cf38e828\&map=6/51.505/14.535 [Accessed 
August 10, 2021].

Francke $H$, Kraume M \& Saadat A. 2013. Thermal-hydraulic measurements and modelling of the brine circuit in a geothermal well. Environ Earth Sci, 70:3481-3495. doi:10.1007/s12665-013-2612-8.

Frick S, Kranz S \& Saadat A. 2010. Holistic Design Approach for Geothermal Binary Power Plants with Optimized Net Electricity Provision. In: Proceedings World Geothermal Congress 2010. Bali, Indonesia, p. 25-29.

Geisinger, (Geothermie Unterhaching) W. 2018. Thermische Leistung und Strombedarf der Geothermieanlage Unterhaching (Personal Communication).

Giese, (Grünwald Equity) K-D. 2018. Betriebsdaten Geothermiekraftwerk Traunreut - Tagesbericht 10.12.2017 (Personal Communication).

GTN. 2010. Klaipeda Report - Investigations Into Injection Problems in Sandstone Aquifers, Geothermie Neubrandenburg. $10 \mathrm{p}$.

Hubacher P, Carlos B \& Max E. 2008. Feldmonitoring und Analysen an Grosswärmepumpen (Phase 2), Bundesamt für Energie BFE. p.

Kamila Z, Kaya E \& Zarrouk SJ. 2021. Reinjection in geothermal fields: An updated worldwide review 2020. Geothermics, 89:375-6505. doi:10.1016/j.geothermics.2020.101970.

Kastner O, Sippel J \& Zimmermann G. 2015. Regional-scale assessment of hydrothermal heat plant capacities fed from deep sedimentary aquifers in Berlin/Germany. Geothermics, 53:353-367. doi:10.1016/j.geothermics.2014.06.002.

Kölbel T, Eltrop L, Walker-Hertkorn S et al. 2009. Nutzung der Tiefengeothermie in Stuttgart: Durchführung von Wirtschaftlichkeitsberechnungen,p.

Moon H \& Zarrouk SJ. 2015. Efficiency of Geothermal Power Plants : a Worldwide Review. In: New Zealand Geothermal Workshop 2012 Proceedings.

Mouchot J, Genter A, Cuenot N et al. 2018. First Year of Operation from EGS geothermal Plants in Alsace, France : Scaling Issues. In: 43rd Workshop on Geothermal Reservoir Engineering. Stanford, California: Stanford University, p. 1-12.

Pietl, (Stadtwerke München) C. 2018. Vollast-Betriebsparameter von Geothermie-Anlagen der Stadtwerke München (Personal Communication).

Pons M. 2009. On the reference state for exergy when ambient temperature fluctuates. Int J Thermodyn, 12:113-121. doi:10.5541/IJOT.1034000246.

Pratiwi A, Ravier G \& Genter A. 2018. Geothermics Life-cycle climate-change impact assessment of enhanced geothermal system plants in the Upper Rhine Valley. Geothermics, 75:26-39. doi:10.1016/j.geothermics.2018.03.012.

Russ C, Miara M, Platt M et al. 2010. Feldmessung Wärmepumpen im Gebäudebestand, Fraunhofer ISE. 1-21 p.

Schallenberg K, Menzel H \& Erbas K. 1999. Das Geothermische Heizwerk in Neustadt-Glewe im Betriebsjahr 1996. In: GFZ STR99/04. p. 206.

Schlagermann P. 2014. Exergoökonomische Analyse geothermischer Strombereitstellung am Beispiel des Oberrheingrabens. Technische Universität München.

Šliaupa S, Zinevičius F, Mazintas A et al. Geothermal Energy Use, Country Update for Lithuania. In: European Geothermal Congress 2019. Den Haag, p. 11-14. 
1 Straubel D, Ehrlich H, Huenges E et al. 1998. Rechenmodell zur Analyse der Wärmegestehungskosten bei 2 hydrothermaler Nutzung. In: Angebotspotential der Erdwärme sowie rechtliche und wirtschaftliche Aspekte der 3 Nutzung hydrothermaler Ressourcen. Geoforschungszentrum, p. 67-79.

4 Toews M, Riddell D, Vany J et al. 2021. Case Study of a Multilateral Closed-Loop Geothermal System. Proc 5 World Geotherm Congr:1-11.

6 TRIO-CORD KFT. 2012. Müszaki leírás - Geotermikus energiahasznosítás mezőberény város területén 7 geotermikus közmürendszer felépítése megvalósulási (Technical description - Geothermal energy use in the city 8 of Mezőberény), Klaipeda. $104 \mathrm{p}$.

9 Winsloe R, Richter A \& Vany J. 2021. The Emerging (and Proven) Technologies that Could Finally Make 10 Geothermal Scalable. Proc World Geotherm Congr, 2:1-11.

11 Wolfgramm M, Obst K, Rauppach K et al. 2009. Produktivitätsprognosen geothermischer Aquifere in 12 Deutschland. In: Der Geothermiekongress 2009. Bochum, p. 17-19. 


\section{Supplementary Files}

This is a list of supplementary files associated with this preprint. Click to download.

- EnergyconversionfactorsofgeothermalplantsV3.ods

- HPsystemefficienciesV2.ods 